\title{
Evidence in pictures: What's your diagnosis?
}

Hernández-Collazo A*, Ocampo-Garza J**, Poletti-Vázquez D***.



\section{Case Report}

We present the case of a 62-year-old man with long history of increasing swelling of his nose, most notably on the tip of nasal pyramid and less in both alar regions. He was able to squeeze his nose to obtain a hialinus material and complains about snoring during sleep. He developed a disfiguring hypertrophy of his nose and complained of nasal obstruction and a foul odor from his nose.

Our patient is in cardiology outpatient consultation for sleep apnea, he is obese and used to smoke. Last BCC (Blood Cell Count) revealed polyglobulia: $\mathrm{Hb} 19 \mathrm{~g} / \mathrm{dL}$ and Functional pulmonary test results had obstructive and restrictive patterns.

When he presented for dermatologic evaluation, physical examination revealed a painless notable enlarged nose with mild redness and significant nasal sebaceous

* Médico Pasante de Servicio Social. Centro de Ciencias de la Salud de la Universidad Autónoma de Aguascalientes.

** Médico Pasante de Servicio Social Laboratorio de Investigación Dermatológica Universidad Autónoma de Nuevo León.

*** Profesor de Prácticas Clínicas de Dermatología. Centro de Ciencias de la Salud de la Universidad Autónoma de Aguascalientes

Fecha de recibido 12 agosto 2011

Fecha de aceptación 30 agosto 2011

Correspondencia Dr Abraham Adameck Hernández Collazo. Departamento de Medicina del Centro de Ciencias de la Salud. Avenida Universidad \# 940 Teléfono 9108440 Correo electrónico: adam_ck11@hotmail.com 
hypertrophy, cyst and dilated infundibula making a bulbous nodular telangiectatic aspect (potato nose). The treatment was an excision with high-frequency electrosurgery of a big nasal neoplastic mass on the tip and moderate on nostrils. Immediately after, obstructive pulmonary symptoms were notably diminished.

\section{Question:}

1. What's your diagnosis?

a. Localized chronic fibrosing vasculitis.

b. Sebaceous adenoma.

c. Acne rosacea (rhinophyma).

d. Granuloma faciale rhinophyma-like.

2. About Obstructive Sleep Apnea the main etiologic entity in our patient could be:
a. Abnormal Functional Pulmonary Test.
b. Obstructive mass in nose.
c. Tobacco history.
d. Polycythaemia.

\section{Review.}

Rhinophyma is a benign inflammatory soft-tissue hypertrophy of sebaceous glands and connective tissue of the lower half of the nose. Its etiology remains obscure although several causes have been proposed including vitamin deficiencies, stress, androgenic hormones and secondary to invasion of Demodex folliculorum mite. 1 Rhinophyma is considered to be an end stage (fourth stage) of rosacea 2,3 ; there is a male predominance $(12: 1)$ and age of onset is between 40 and 60 years, peaking in the group age older than 65 years 4 , and may be affected by alcohol, caffeine, spicy foods and other vasoactive influences such as climate. ${ }^{5}$

Nowadays, rhinophyma has been classified as the fourth (most advanced) stage of rosacea: the first stage (flushed face) in third decade of life; afterwards (second stage), the skin thickens and telagiectases and persistent facial erythema develop; then some patients progress to the third stage: acne rosacea which occurs around the fifth decade of life with erythematous papules and pustules on malar region, glabella, nose, forehead and chin. Progression to rhinophyma occurs in a small group of individuals. Clinically the nose becomes erythematous: reddishpurple discoloration, hypervascular with telangiectases and in more severe cases the skin may have pits, fissures and scars: enlarged, developing a lobular, nodular appearance. .,6,7 $^{2,7}$

Medical therapy may be an option for very early rhinophyma before scarring and fibrosis have occurred. An oral therapy of Isotretinoin or antibiotics as tetracycline, erythromycin, ampicillin and metronidazole have been useful in eliminating prominent pustules, like topical metronidazole, another medical option in the treatment of early rhinophyma. For established rhinophyma, surgical modalities like dermabrasion, scalpel excision, electrosurgery, shaw knife, laser, harmonic scalpel and cryosurgery are the accepted treatment. The surgical treatment with high-frequency electrosurgery is preferred because it's quick, efficient and low in cost. Wound care consists of frequent application of petroleum jelly as an emollient. Postoperative recovery is essentially pain-free, with quick tissue 
reepithelialization and a good cosmetic result, making it ideal for the treatment of rhinophyma in an outpatient setting. Unlike Laser CO2, that is an effective and durable treatment for rhinophyma with a low risk of side-effects and is associated with high patient acceptability and satisfaction, but associated with postoperative pain. 5,9

Severe rhinophyma is a disfiguring and sociallystigmatizingcondition, characterized by lay terms such as "whisky" or "rum" nose and "grog blossom". Although many patients with a severe degree of rhinophyma had nasal obstruction, their primary concern is usually to treat the severe cosmetic deformity even more than nasal airway compromise. ${ }^{4,5}$, The increased size from gross enlargement and blood flow to the nasal tissue may even cause nasal obstruction, making it difficult to breath normally. Nasal obstruction is a risk factor for snoring associated to sleep apnea or not. ${ }^{8}$

The main etiologic causes producing obstructive sleep apnea syndrome (OSA) are anatomical and functional upper airway alterations, including obesity, regardless clinical obesity degree, due fat deposit in upper airway walls and oropharynx or nostrils anatomical anomalies. ${ }^{10,} 11$ Nasal obstruction caused by a deformity of the nasal external morphology like severe rhinophyma in patients, could be the main etiologic entity in OSA Syndrome; therefore the value for a complete upper airway examination including nose airway (nasal valve). ${ }^{10}$ Then, the results from OSA appears (sleepiness, chronic respiratory failure, abnormal functional pulmonary test and polycythaemia). In our patient, obstructive symptoms disappeared once nose mass recession, hence we can affirm that an anatomical upper obstruction due a nostril anomaly caused the OSA in a risky patient (obese). Other risk factors include general medical conditions conducing motility disfunction like muscular diseases (myotonic dystrophy), or upper airway obstruction like endocrinological diseases hypothyroidism, acromegaly, etc. ${ }^{11}$

\section{References}

1. Stucker FJ, Lian T, Saners K. The ABCs of rhinophyma. Am J Rhinol 2003;17:45-9.

2. Apikian M, Goodman G, Roberts S. Management of Mild to Moderate Rhinophyma with a 1,450-nm Diode Laser: Report of Five Patients. Dermatol Surg 2007;33:847-850

3. Rebora A. The red face: rosacea. Clin Dermatol 1993;11:225-34.

4. Wollina U. Rosacea and rhinophyma in the elderly. Clin Dermatol. 2011 Jan-Feb; 29(1):61-8.

5. Aferzon M, Millman B. Excision of Rhinophyma with High-Frecuency Electrosurgery. Dermatol Surg 2002;28:735-738.

6. Powell F. Rosacea. N Engl J Med 2005; 352:793803.
7. Wilkin JK. Rosacea: pathophysiology and treatment. Arch Dermatol 1994;130:359-62.

8. Young $T$, Finn L, Palta M. Chronic nasal congestion at night is a risk factor for snoring in a population-based cohort study. Arch Intern Med 2001; 161:15141519.

9. Madan V, Ferguson JE, August PJ. Carbon dioxide laser treatment of Rhinophyma- A review of $124 \mathrm{pa}-$ tients. Br J Dermatol. 2009;161:814-8.

10. Álvarez-Sala JL, Calle M, Fernández JM, Martínez R, Rodríguez JL. Apnea obstructiva del sueño. Inf Ter Sist Nac Salud. 1999;23: 121-31.

11. Redline S, Strohl KP. Recognition and consequences of obstructive sleep apnea hypopnea syndrome. Clin Chest Med 1998;19:1-19. 

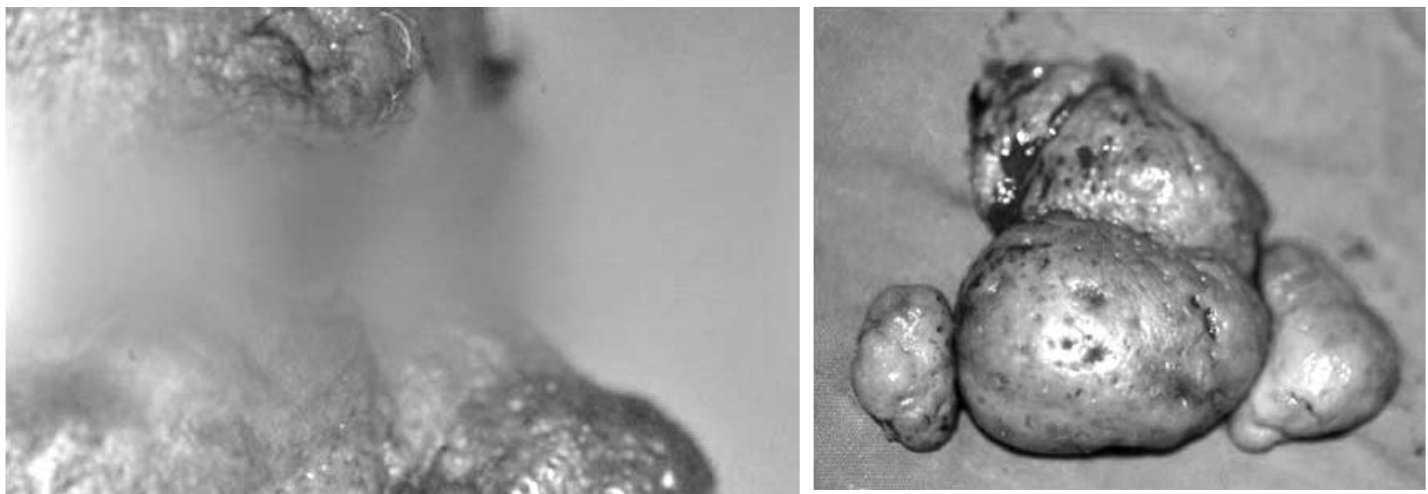

Fig 3. Surgical specimen obtained through electrosurgery, after removal obstructive pulmonary symptoms notably diminished.

Fig 2. Front picture of our patient, notable enlarged nose with mild redness and significant nasal sebaceous hypertrophy, cyst and dilated infundibula making a bulbous nodular telangiectatic aspect (potato nose).

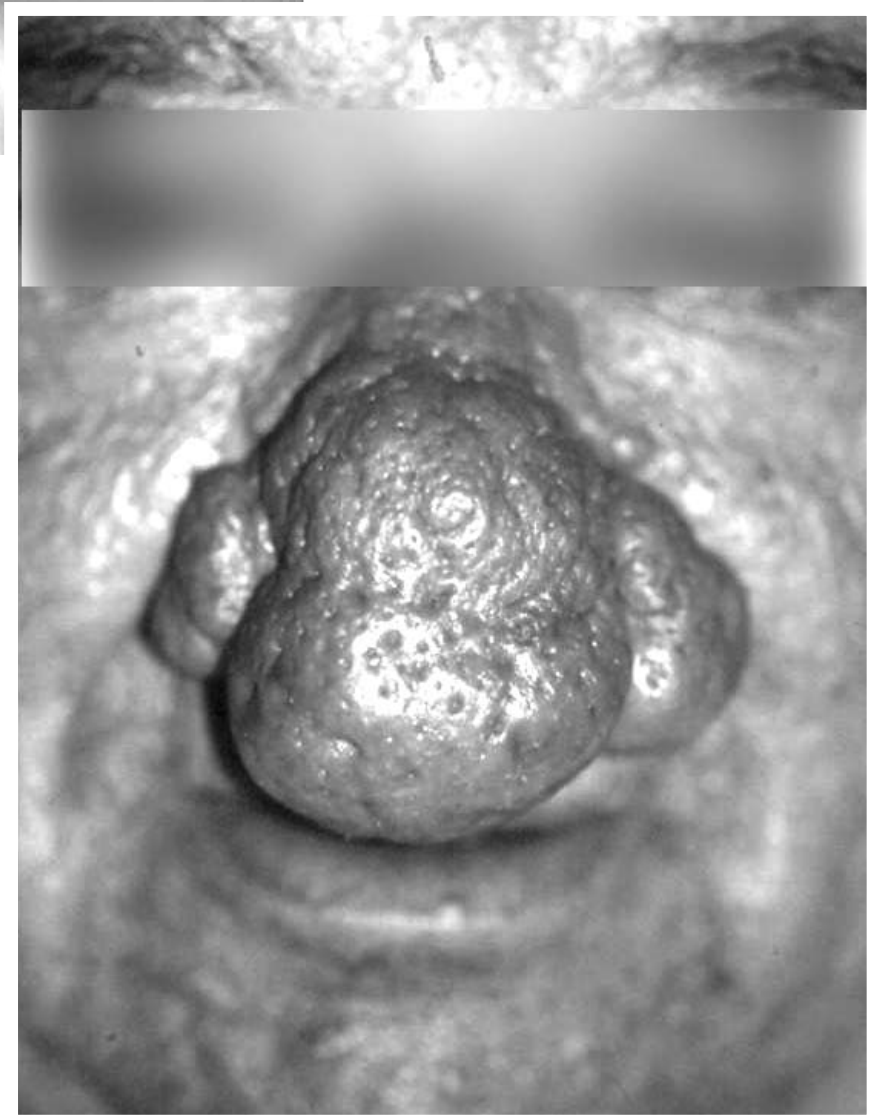




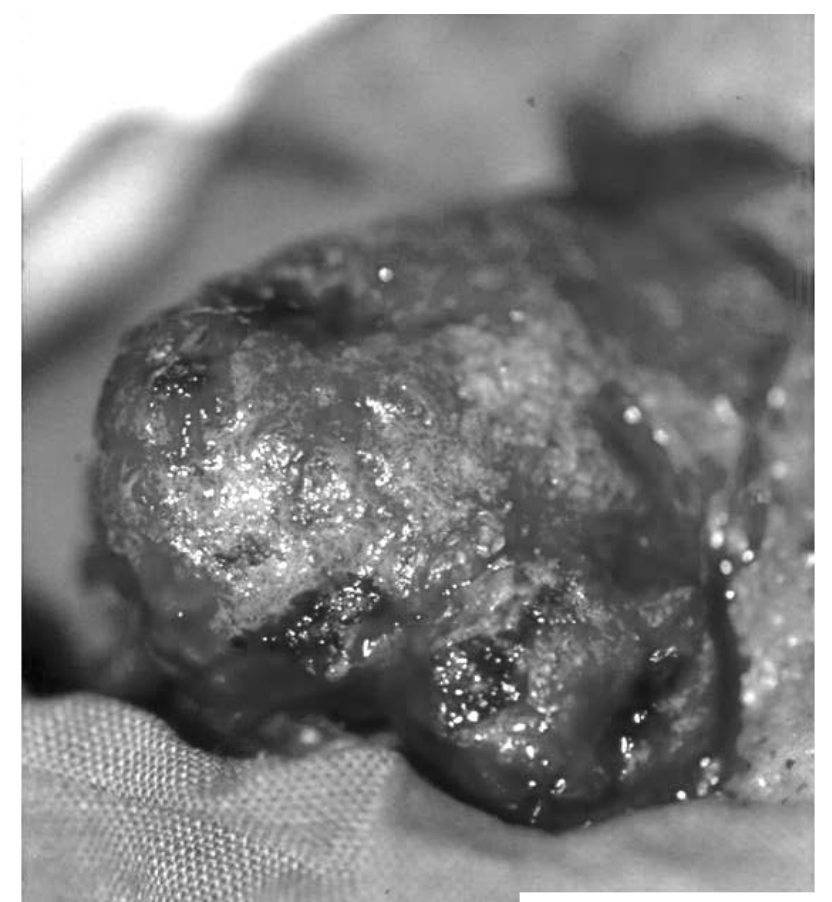

Fig 4. Immediate postoperative picture.

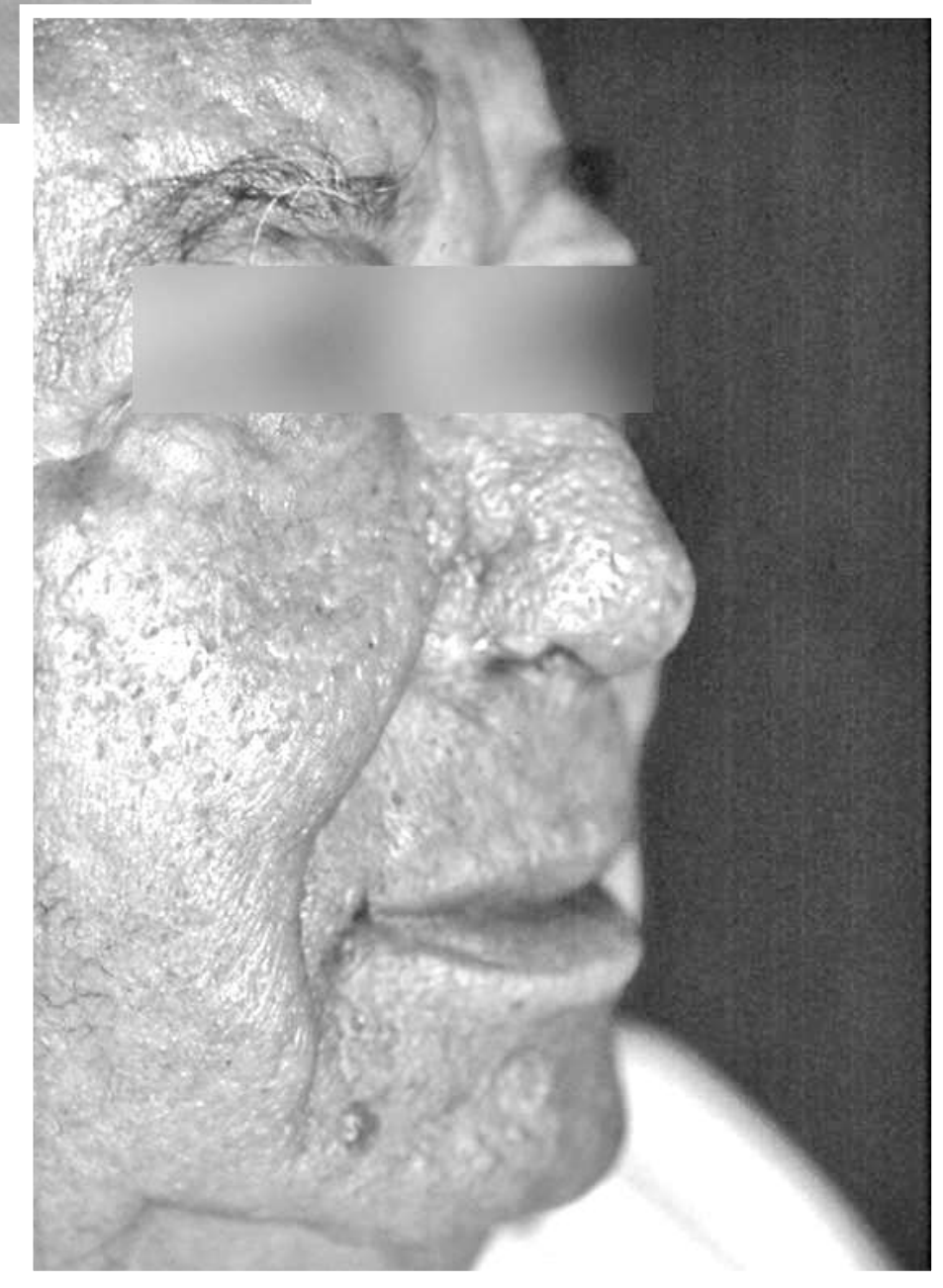
of decreased nasal deformity. 